\title{
Development and application of real-time PCR for specific detection of Lepeophtheirus salmonis and Caligus elongatus larvae in Scottish plankton samples
}

\author{
Alastair J. A. McBeath*, Michael J. Penston, Michael Snow, Paul F. Cook, \\ Ian R. Bricknell, Carey O. Cunningham
}

FRS Marine Laboratory, PO Box 101, Victoria Road, Aberdeen AB11 9DB, UK

\begin{abstract}
Lepeophtheirus salmonis and Caligus elongatus are important parasites of wild and cultured salmonids in the Northern Hemisphere. These species, generically referred to as sea lice, are estimated to cost the Scottish aquaculture industry in excess of $£ 25$ million per annum. There is great interest in countries such as Ireland, Scotland, Norway and Canada to sample sea lice larvae in their natural environment in order to understand lice larvae distribution and improve parasite control. Microscopy is currently relied on for use in the routine identification of sea lice larvae in plankton samples. This method is, however, limited by its time-consuming nature and requirement for highly skilled personnel. The development of alternative methods for the detection of sea lice larvae which might be used to complement and support microscopic examinations of environmental samples is thus desirable. In this study, a genetic method utilising a real-time PCR Taqman ${ }^{\circledR}$-MGB probe-based assay targeting the mitochondrial cytochrome oxidase I (mtCOI) gene was developed, which allowed species-specific detection of $L$. salmonis and C. elongatus larvae from unsorted natural and spiked plankton samples. Real-time PCR is a rapid, sensitive, highly specific and potentially quantitative technique. This study demonstrated its suitability for the routine identification of $L$. salmonis and $C$. elongatus in mixed plankton samples. The real-time PCR assay developed has considerable potential for use in complementing, supporting and reducing reliance on time-consuming conventional microscopic examination for the specific identification of sea lice larvae in plankton samples.
\end{abstract}

KEY WORDS: Lepeophtheirus salmonis $\cdot$ Caligus elongatus $\cdot$ Sea lice $\cdot$ Taqman ${ }^{\circledR}$-MGB $\cdot$ Real-time PCR $\cdot$ Cytochrome oxidase I

\section{INTRODUCTION}

Sea lice are marine ectoparasitic copepods belonging to the family Caligidae. Lepeophtheirus salmonis (Krøyer, 1837) and Caligus elongatus (von Nordmann, 1832) are the most common sea lice species affecting salmonids in Scotland and Norway (Pike \& Wadsworth 1999). These pathogens have become increasingly important with the development of the salmon aquaculture industry, and are capable of inflicting extensive damage when present in high numbers (Wootten \& Smith 1982, Johnson et al. 2004). L. salmonis is considered to be the most economically important sea louse affecting Scottish salmon aquaculture (Revie et al. 2002). Estimates of Scottish salmon farming spending in regard to sea lice control suggest costs of over E25 million annually (Pike \& Wadsworth 1999, Rae 2002). It is largely salmonid specific, whereas C. elongatus has a much wider host range (Pike \& Wadsworth 1999). With the increase in aquaculture of other fish such as gadoids, C. elongatus could potentially become a more serious aquaculture pathogen (Bricknell et al. 2006, Øines et al. 2006).

The Lepeophtheirus salmonis life cycle has 10 stages, separated by moults and divided into 5 identifiable phases. The egg hatches into the first of 2 nauplius stages which are free-swimming, allowing dispersal via sea currents. This is followed by the infective 
copepodid stage; copepodids are initially free-swimming until they settle on a suitable host. Following attachment, there are 4 chalimus stages and 2 preadult stages, by which point the parasite is feeding. The final stage is the adult phase which is full maturity, and the female produces paired egg-strings to begin the cycle once more (Johnson \& Albright 1991a, Schram 1993). Caligus elongatus differs in that it does not possess the 2 pre-adult stages (Piasecki 1996), the chalimus IV stage moulting directly into the sexually active adult. For L. salmonis the longevity of the nauplius and copepodid stages in the plankton is dependent on temperature. The nauplius survives for $4 \mathrm{~d}$ at $10^{\circ} \mathrm{C}$ and the copepodid remains infectious for approximately $10 \mathrm{~d}$ (Johnson \& Albright 1991b), which allows a window of opportunity for detection before the infective stages establish themselves on a host.

Planktonic louse larvae have been sampled from sea water along the west coast of Ireland and Scotland to investigate the distribution and transport of louse larvae in their natural environment in an effort to understand the potential for cross-infection between wild and farmed fish and vice versa, and to ultimately improve parasite control (Costelloe et al. 1996, 1998a,b, McKibben \& Hay 2004, Penston et al. 2004). However, to date there is controversy regarding the distribution of sea louse larvae and also in relation to the distribution of parasitic sea lice collected from fish (Asplin et al. 2004, Brooks 2005, Krkošek et al. 2005, 2006, Brooks \& Stucchi 2006, Murray \& Gillibrand 2006). Conventional methods of larval lice detection and identification involve sample collection and microscopy to manually scan the samples for sea lice larvae, followed by a close morphological examination of each individual specimen. The microscopic method is limited by the difficulty in identifying nauplii stages, and identifying many copepodids is an onerous process (Schram 2004). Therefore, an alternative method of identification which would overcome these limitations is desirable. Genetic approaches provide a useful alternative to the more traditional microscopic sorting. There have been several molecular methods used to aid in identification of planktonic organisms, such as oligonucleotide probes (Medeiros-Bergen et al. 1995), restriction fragment length polymorphism (RFLP) analysis (Lindeque et al. 1999, 2004), multiplexed species-specific polymerase chain reaction (PCR) (Bucklin et al. 1999, Hill et al. 2001) and 2-step nested PCR (Deagle et al. 2003). The mitochondrial cytochrome oxidase I (mtCOI) gene, targeted in several of these studies (Bucklin et al. 1999, Hill et al. 2001, Deagle et al. 2003), is commonly used in phylogenetic analysis and species identification because it contains both variable and conserved regions in close proximity to one another. This gene has previously been used to discriminate between several species of Calanus (Copepoda: Calanoida) (Bucklin et al. 1999, Hill et al. 2001).

In the present study, a real-time PCR Taqman ${ }^{\circledR}$-MGB probe-based assay targeting the COI gene has been used to allow species-specific detection of Lepeophtheirus salmonis and Caligus elongatus nauplii and copepodids from unsorted plankton samples. Real-time PCR is rapid $(<2 \mathrm{~h})$, is more sensitive and offers improved specificity over conventional PCR by utilising a primer pair and a highly specific secondary probe. The results are available immediately, negating the need for agarose gel electrophoresis analysis. It also provides the potential for development of quantitative assays.

\section{MATERIALS AND METHODS}

Sample collection and preparation. Adult Lepeophtheirus salmonis and Caligus elongatus samples were collected from Atlantic salmon Salmo salar freshly caught in nets off the NE coast of Scotland and stored separately in $100 \%$ ethanol. Females possessing egg strings were targeted to differentiate the 2 species in the field. Copepodids of both species, hatched in the laboratory from egg strings of identified adult lice were stored in $100 \%$ ethanol. These copepodids were used both directly and for spiking of plankton samples

For the preliminary testing, plankton samples from the east coast of Scotland, $3 \mathrm{~km}$ off Stonehaven, were collected using a $1 \mathrm{~m}$ ring net fitted with a $200 \mu \mathrm{m}$ mesh and a non-filtering cod-end towed behind a slow-moving boat, then subjected to filtration through a $250 \mu \mathrm{m}$ filter, retained on a $100 \mu \mathrm{m}$ filter and stored in $100 \%$ ethanol at $4{ }^{\circ} \mathrm{C}$.

In order to apply the probes to environmental plankton samples, qualitative samples were collected inside the cages of 2 separate salmon farms and a cod farm, at 5 and $20 \mathrm{~m}$ distant from a salmon farm and from near the shoreline of a fish-farmed sea loch. The methods of sample collection were based on methods previously used (Jackson et al. 1994, Costelloe et al. 1996, 1998a,b, McKibben \& Hay 2004, Penston et al. 2004). Sample collection within the cages at the salmon and cod farms was conducted by hauling a plankton net with a mesh size of $200 \mu \mathrm{m}$ and a mouth diameter of $0.3 \mathrm{~m}$ diameter, across the cages from one side to the other $(20 \mathrm{~m})$ 4 times. Samples were collected 5 and $20 \mathrm{~m}$ away from salmon cages by towing a plankton net of $150 \mu \mathrm{m}$ mesh near the surface behind a rigid, slow-moving, inflatable boat. Samples were also collected near the shoreline by wading a known distance while towing a $140 \mu \mathrm{m}$ mesh plankton net. All samples were preserved in $100 \%$ alcohol.

A double blind trial was carried out using these samples. Two identical sample sets were prepared, 1 for 
microscopy and 1 for real-time PCR. Samples were mixed thoroughly and then passed consecutively 3 times through a bifurcated funnel. Division in this way yielded 8 sub-samples. Washings were collected with each sample. The samples were collected in conical flasks and then transferred to $50 \mathrm{ml}$ centrifuge tubes. Each of the 2 sample sets included 1 unspiked and 3 spiked (+1, 10 or 100 Lepeophtheirus salmonis copepodids directly from storage in ethanol) sub-samples from each of the various locations as well as several artificial samples prepared in the laboratory (Table 1).

Table 1. Lepeophtheirus salmonis (L.s.) and Caligus elongatus (C.e.). Number of copepodids identified by microscopy, and real-time PCR cycle threshold values $\left(C_{\mathrm{T}}\right)$ obtained using sea lice probes tested blind on various spiked and unspiked Scottish environmental samples and 3 synthetic laboratory samples using $0.1 \mathrm{ng} \mathrm{ul}^{-1}$ DNA per reaction over a single plate. Samples 1 to 12 and 21 to 24 taken from sea loch on the west coast of Scotland; Predict. L.s. pos.: level of positivity expected (+: low, ++++: very high number, -: none); nd: not detected (samples negative by real-time PCR)

\begin{tabular}{|c|c|c|c|c|c|c|c|}
\hline \multirow{2}{*}{$\begin{array}{l}\text { Origin/ } \\
\text { Sample no. }\end{array}$} & \multirow{2}{*}{$\begin{array}{c}\text { Dry wt } \\
\text { (mg) }\end{array}$} & \multirow{2}{*}{$\begin{array}{l}\text { No. L.S. } \\
\text { added }\end{array}$} & \multirow{2}{*}{$\begin{array}{l}\text { Predict. } \\
\text { L.S. pos. }\end{array}$} & \multicolumn{2}{|c|}{$C_{\mathrm{T}}$ value } & \multicolumn{2}{|c|}{ Microscopic counts } \\
\hline & & & & C.e. & L.S. & L.S. ${ }^{\mathrm{a}}$ & C.e. \\
\hline \multicolumn{8}{|c|}{ At salmon cage } \\
\hline 1 & 260 & 0 & + & 37.32 & nd & 0 & 0 \\
\hline 2 & 300 & 1 & + & 36.49 & nd & 1 & 0 \\
\hline 3 & 350 & 10 & ++ & 32.21 & nd & 9 & 0 \\
\hline 4 & 350 & 100 & +++ & 29.18 & nd & $>100$ & 0 \\
\hline \multicolumn{8}{|c|}{ Near salmon cage } \\
\hline 5 & 250 & 0 & - & nd & nd & $1^{\mathrm{b}}$ & 0 \\
\hline 6 & 260 & 1 & + & 36.18 & nd & 0 & 0 \\
\hline 7 & 290 & 10 & ++ & 34.08 & nd & 7 & 0 \\
\hline 8 & 420 & 100 & +++ & 29.8 & nd & $>100$ & 0 \\
\hline \multicolumn{8}{|c|}{$20 \mathrm{~m}$ from salmon cage } \\
\hline 9 & 230 & 0 & - & nd & nd & 0 & 0 \\
\hline 10 & 240 & 1 & + & 39.27 & nd & 0 & 0 \\
\hline 11 & 320 & 10 & ++ & 33.84 & nd & 4 & 0 \\
\hline 12 & 370 & 100 & +++ & 30.79 & nd & $>100$ & 0 \\
\hline \multicolumn{8}{|c|}{ Shetland, at salmon cage } \\
\hline 13 & 230 & 0 & + & nd & 40.92 & 0 & 0 \\
\hline 14 & 280 & 1 & + & 38.06 & 36.2 & 1 & 0 \\
\hline 15 & 390 & 10 & ++ & 32.08 & nd & 3 & 0 \\
\hline 16 & 410 & 100 & +++ & 29.93 & nd & $>100$ & 0 \\
\hline \multicolumn{8}{|l|}{ At cod cage } \\
\hline 17 & 260 & 0 & - & 37.02 & 37.43 & $1^{\mathrm{b}}$ & 0 \\
\hline 18 & 240 & 1 & + & 35.53 & nd & 1 & $0^{\mathrm{c}}$ \\
\hline 19 & 270 & 10 & ++ & 33.1 & nd & 8 & 1 \\
\hline 20 & 250 & 100 & +++ & 29.52 & nd & $>100$ & 0 \\
\hline \multicolumn{8}{|l|}{ Shore } \\
\hline 21 & 310 & 0 & - & nd & nd & 0 & 0 \\
\hline 22 & 480 & 1 & + & nd & nd & 1 & 0 \\
\hline 23 & 330 & 10 & ++ & 34.12 & nd & 7 & 0 \\
\hline 24 & 290 & 100 & +++ & 30.79 & nd & $>100$ & 0 \\
\hline \multicolumn{8}{|l|}{ Laboratory } \\
\hline 25 & 250 & $\begin{array}{l}100 \text { L.S. } \\
2 \text { C.e. }\end{array}$ & $\begin{array}{c}+++ \\
+\end{array}$ & 28.27 & 36.26 & 95 & 0 \\
\hline 26 & 240 & $\begin{array}{l}0 \text { L.S. } \\
4 \text { C.e. }\end{array}$ & $\begin{array}{l}- \\
+\end{array}$ & nd & 41.75 & 4 & 4 \\
\hline 27 & 1580 & 1000 & ++++ & 28.45 & nd & $\sim 1000$ & 0 \\
\hline \multicolumn{8}{|c|}{$\begin{array}{l}\text { a In samples with }>10 \text { copepodids, assumption of identity of all copepodids } \\
\text { was based on sub-sample of } 10 \text { identified copepodids } \\
\text { b One caligid copepodid found, but species could not be determined due to } \\
\text { poor specimen condition } \\
\text { c Two post-larval stages found }\end{array}$} \\
\hline
\end{tabular}

DNA extraction. DNA was extracted from individual and pooled adult lice samples using the Wizard $^{\circledR}$ Genomic DNA Purification Kit (Promega) according to the manufacturer's protocol except half the stated quantities of all reagents were used and the duration of all centrifugation steps was doubled. The concentration of DNA extracted was estimated by $1 \%$ agarose gel electrophoresis alongside a Low DNA Mass Ladder (Invitrogen).

DNA samples of Lepeophtheirus salmonis from pink salmon Oncorhynchus gorbuscha, L. hospitalis from quillback rockfish Sebastes maliger, L. parvicruris from starry flounder Platichthys stellatus and Caligus clemensi from chum salmon $O$. keta were kindly provided by Simon Jones (Pacific Biological Station, Nanaimo, Canada).

The DNA of individual and pooled copepodids was obtained by incubation of samples at $55^{\circ} \mathrm{C}$ overnight in $5 \mu \mathrm{l}$ lysis buffer containing $1 \times$ TE buffer, $0.45 \%$ Tween 20 (Sigma), $0.45 \%$ IGEPAL-CA630 (Sigma), $20 \mathrm{mg} \mathrm{ml}^{-1}$ Proteinase-K (Sigma) followed by $95^{\circ} \mathrm{C}$ for $5 \mathrm{~min}$ to inactivate the enzyme.

The total DNA of spiked and unspiked environmental plankton samples was extracted using the DNeasy ${ }^{\circledR}$ Tissue Kit (Qiagen) following the manufacturer's animal tissue protocol with some initial modifications. The samples were allowed to settle-out while in storage and most of the ethanol was carefully removed without disturbing the plankton. The remaining liquid was allowed to evaporate and the dry weight was measured. The sample was resuspended in $180 \mu$ l of Buffer ATL (Qiagen) and $20 \mu l$ Proteinase-K (Qiagen) for every $25 \mathrm{mg}$ of sample and lysed at $55^{\circ} \mathrm{C}$ overnight. For samples $>25 \mathrm{mg}$ in dry weight, an aliquot of $200 \mu$ lysate was used in each subsequent DNeasy reaction. Three separate aliquots were initially used for each sample processed in this way to show reproducibility of the DNeasy extraction method. The presence and concentration of DNA was estimated by $1 \%$ agarose gel electrophoresis alongside a Low DNA Mass Ladder (Invitrogen). All DNA samples were stored at $-20^{\circ} \mathrm{C}$.

Sequence data. PCR was performed to amplify a fragment of approximately $700 \mathrm{bp}$ of the COI gene from DNA 
obtained from Lepeophtheirus salmonis, Caligus elongatus, C. clemensi and L. hospitalis using the 'universal' primers LCO1490 5'-GGT CAA CAA ATC ATA AAG ATA TTG G-3' and HCO2198 5'-TAA ACT TCA GGG TGA CCA AAA AAT CA-3' (Folmer et al. 1994) in $20 \mu \mathrm{l}$ reactions containing $1 \times \mathrm{NH}_{4}$ buffer, $1.5 \mathrm{mM}$ $\mathrm{MgCl}_{2}, 10 \mathrm{mM}$ dNTPs (Invitrogen), $1.4 \mathrm{mM}$ of each primer and $5 \mathrm{U}$ Taq polymerase (Bioline). Cycling conditions were adapted from Bucklin et al. (1999) with the annealing step reduced to $90 \mathrm{~s}$ and the extension step reduced to $2 \mathrm{~min}$ (initial denaturation at $94^{\circ} \mathrm{C}$ for 5 min followed by 40 cycles of $94^{\circ} \mathrm{C}$ for $1 \mathrm{~min}, 37^{\circ} \mathrm{C}$ for $90 \mathrm{~s}, 72^{\circ} \mathrm{C}$ for $2 \mathrm{~min}$ ). PCR products were purified using the Geneclean III Gel Purification Kit (Bio 101, Anachem) and concentrations estimated by $1 \%$ agarose gel electrophoresis using a Low DNA Mass Ladder. PCR products were cloned using the $\mathrm{pGEM}^{\circledR}-\mathrm{T}$ Easy Kit (Promega) according to the manufacturer's protocol and purified using the Wizard ${ }^{\circledR}$ Plus MiniPrep DNA Purification System (Promega). Clones containing inserts of the correct size were sequenced using the primers LCO1490, HCO2198, T7 5'-TAA TAC GAC TCA CTA TAG GG-3' and Sp6 5'-ATT TAG GTG ACA CTA TAG AAT ACT CAA GC-3' (flanking the insertion site), and the Big Dye ${ }^{\mathrm{TM}}$ Ready Reaction Mix Version 3.1 (Applied Biosystems) according to the manufacturer's protocol. Sequencing was performed on an ABI 377 automated DNA-sequencer (Applied Biosystems) and the resulting sequence was analysed and consensus sequences constructed for each species using the Sequencher software (Gene Codes). These consensus sequences were verified by comparison with $L$. salmonis and C. elongatus COI sequences (AY386272-386274; AY861361-861371) kindly provided by Øivind Øines and Peter Heuch (National Veterinary Institute, Oslo, Norway) (Øines \& Heuch 2005). Partial COI sequence was also obtained for L. hospitalis and C. clemensi and submitted to the EMBL database (AM235887 and AM235888 respectively).

Real-time PCR. Primers and Taqman ${ }^{\circledR}$-MGB probes (see Fig. 1), were designed using Primer Express Version 2.0 software (Applied Biosystems) for both Lepeophtheirus salmonis and Caligus elongatus in order to distinguish these 2 species. The chosen sequences were subjected to a BLAST search to check the GenBank database for any similar sequences and potential cross-reaction.

Assays were performed on an Applied Biosystems 7000 Sequence Detection System programmed to conduct the following cycling profile: $50^{\circ} \mathrm{C}$ for $2 \mathrm{~min}$ (AmpErase ${ }^{\circledR}$ uracil N-glycosylase incubation), $95^{\circ} \mathrm{C}$ for 10 min (AmpliTaq Gold polymerase activation) followed by 45 cycles of $95^{\circ} \mathrm{C}$ for $15 \mathrm{~s}$ (denaturation) and $60^{\circ} \mathrm{C}$ for $1 \mathrm{~min}$ (annealing/extension). Reactions were conducted in a final volume of $20 \mu$ l containing $1 \mu \mathrm{l}$
DNA template, $1 \times$ Taqman $^{\circledR}$ Universal PCR Mastermix, $900 \mathrm{nM}$ of each primer and $200 \mathrm{nM}$ Taqman $^{\circledR}$ probe (all Applied Biosystems). If the reactions involved the use of Taqman ${ }^{\circledR}$ Exogenous Internal Positive Control (IPC) Reagents (Applied Biosystems), to check for PCR inhibition, the reaction conditions were identical but included $1 \times$ Exo IPC mix and $1 \times$ Exo IPC DNA. Each assay using IPCs also contained a minimum of 3 no target control (NTC) reactions to obtain optimum cycle threshold $\left(C_{\mathrm{T}}\right)$ values for the IPC DNA in the absence of target DNA or inhibitors and 2 no amplification control (NAC) reactions, the latter of which also contained $1 \times$ Exo IPC block.

The efficiencies of the primers and probes were assessed using triplicate 10 -fold serial dilutions of a single lysed copepodid of each species and plotting the mean $C_{\mathrm{T}}$ values on a standard curve. The slope of the calibration curve indicates the efficiency of the reaction.

Probe testing. Preliminary testing of the Lepeophtheirus salmonis probe on plankton samples was performed using replicate $(n=3)$ samples obtained from Stonehaven, on the east coast of Scotland. Due to the absence of a major salmonid river and salmon farms at this location, these samples were believed to be free from L. salmonis but may have contained Caligus elongatus. Indeed, several pre-adult specimens of Caligus sp. were removed from these plankton samples. The natural presence of $C$. elongatus would have altered the results obtained following spiking and therefore the $C$. elongatus probe was not tested on these samples. Samples used were all 25 to $30 \mathrm{mg}$ planktonic material which were either neat or spiked with 1 or 10 L. salmonis copepodids prior to the DNA extraction step described above.

Probe application. Both probes were applied to a double blind set of environmental samples from various locations, some of which had also been spiked with copepodids of Lepeophtheirus salmonis and/or Caligus elongatus, as described earlier (Table 1). DNA from each plankton sample was initially extracted in triplicate and, using the DNA concentration estimates, each extracted DNA sample was diluted to $1 \mathrm{ng}^{-1} \mathrm{l}^{-1}$ in Elution Buffer AE (Qiagen). Ten-fold serial dilution series to $10^{-4}$ were prepared from this material, on which both probes were tested. The $0.1 \mathrm{ng}^{-1} \mathrm{l}^{-1}$ (i.e. $10^{-1}$ dilution) concentration was selected to minimise potential inhibition caused by higher template concentrations, and the assay was repeated with all samples on a single plate to allow comparison with both probes.

Microscopy. Samples were washed over a pair of stacked sieves. The upper mesh of $500 \mu \mathrm{m}$ was used to remove coarse material and the lower mesh of $150 \mu \mathrm{m}$ retained the fraction of the sample for analysis. The retained material was sorted under a Zeiss SV11 dis- 
section microscope at a magnification of 100, and caligid copepod larvae were counted and removed. Copepodids were identified using a Zeiss Axiovert 200 microscope at a magnification of 200 to $400 \times$. In samples with greater than 10 copepodids, a sub-sample of 10 copepodids was identified. No attempt was made to identify the nauplius stages. Copepodids were identified by size, armature of the maxilliped and morphology of the prosome and the second segment of the urosome (Schram 2004). Pigmentation characteristics were not used in determining copepodid species because of bleaching of pigments stored in alcohol.

\section{RESULTS}

The approximate dry weights of all the samples used in the double blind trial ranged from 230 to $480 \mathrm{mg}$, with one 'outlier' of $1580 \mathrm{mg}$ (Table 1). The DNA extractions, using varying quantities of Buffer ATL (+ Proteinase-K) to account for the differing dry weights, produced DNA concentrations of 2 to $12 \mathrm{ng}^{-1} \mathrm{l}^{-1}$, with one extraction yielding $<1 \mathrm{ng} \mathrm{ll}^{-1}$.

\section{Probe efficacy}

Primer and probe sets were created to detect and differentiate Lepeophtheirus salmonis and Caligus elongatus species, and each primer differs from the other species by a minimum of 7 bases but, more importantly, the 2 probes differ by 8 bp (Fig. 1). Both probes were specific for the correct species.

The Lepeophtheirus salmonis probe was positive for the L. salmonis from pink salmon, but negative for the other closely related species L. hospitalis, L. parvicruris and Caligus clemensi. The C. elongatus probe was negative for all these species tested (data not shown).

The 2 assays had comparable efficiencies (Fig. 2). For both reaction series there was a high correlation

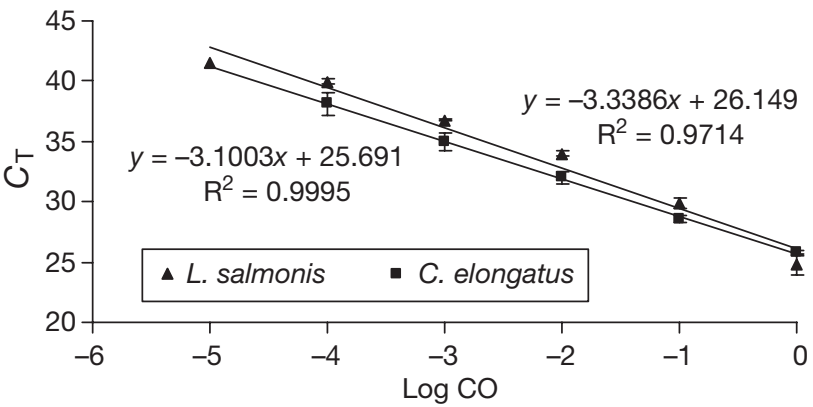

Fig. 2. Lepeophtheirus salmonis and Caligus elongatus. Realtime PCR efficiencies of sea lice probes tested on 10-fold dilution series of DNA from single-lysed copepodids. Standard curve showing cycle threshold $\left(C_{\mathrm{T}}\right)$ values plotted against logarithm of the initial DNA template (Log CO) (1/5th single copepodid lysate). Data are means $\pm \mathrm{SE}_{;} \mathrm{n}=3$

between cycle number and dilution factor, $\mathrm{R}^{2}=0.97$ for Lepeophtheirus salmonis and $\mathrm{R}^{2}=1.0$ for Caligus elongatus. Slope values of -3.34 and -3.10 for L. Salmonis and $C$. elongatus respectively approached the theoretical value of -3.32 , indicating efficient amplification in both assays.

\section{Preliminary probe testing}

Plankton samples collected from an area remote from a major salmonid river (Stonehaven) were negative for Lepeophtheirus salmonis, as expected. The $L$. salmonis probe was able to detect 10 copepodids (Fig. 3a) and a single copepodid (Fig. 3b) when contained within a spiked plankton sample of approximately $30 \mathrm{mg}$ dry weight. $C_{\mathrm{T}}$ values of replicate reactions were comparable although variation was slightly higher between multiple samples (Fig. 3c).

Inhibition of amplification was detected at higher starting DNA template concentrations (Table 2). The inclusion of the IPCs proved this could be diluted out. Undiluted Sample A had an IPC $C_{\mathrm{T}}$ value of

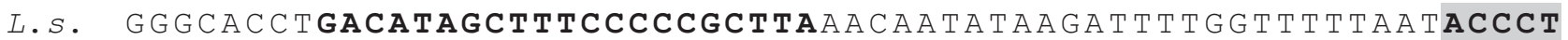 C.e. GTGCGCCAGATATGGCATTTCCTCGCCTGAATAATATAAGTTTTGATTTTTGATACCGT

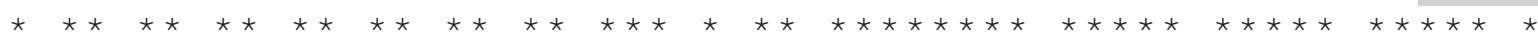

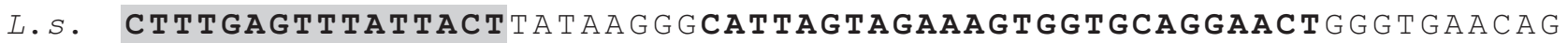 C.e. CACTAACACTACTACTTTAAGRGCTCTTGTTGAAAGGGGTGCAGGTACAGGGTGA CAG}

Fig. 1. Lepeophtheirus salmonis (L.s.) and Caligus elongatus (C.e.). Design of real-time PCR primers (designated LsalmonisCOIfor and LsalmonisCOIrevA and CelongatusCOIfor and CelongatusCOIrev respectively) and 5' 6-FAM labelled Taqman-MGB probes (designated LsalmonisCOI and CelongatusCOI respectively). Amplicon sizes are 102 bp (L.s.) and 92 bp (C.e.). Sequences are shown in single-strand 5'-3' direction; therefore reverse primer sequences reversed and complimented are 5'-AGTTCCTGCACCACTTTCTACTAATG-3' (LsalmonisCOIrevA) and 5'-ctgcaccctttcaacaagag-3' (CelongatusCOIrev). Arrows: primers highlighted in bold and forward/reverse direction; shaded area highlights probes; * : identical bases 

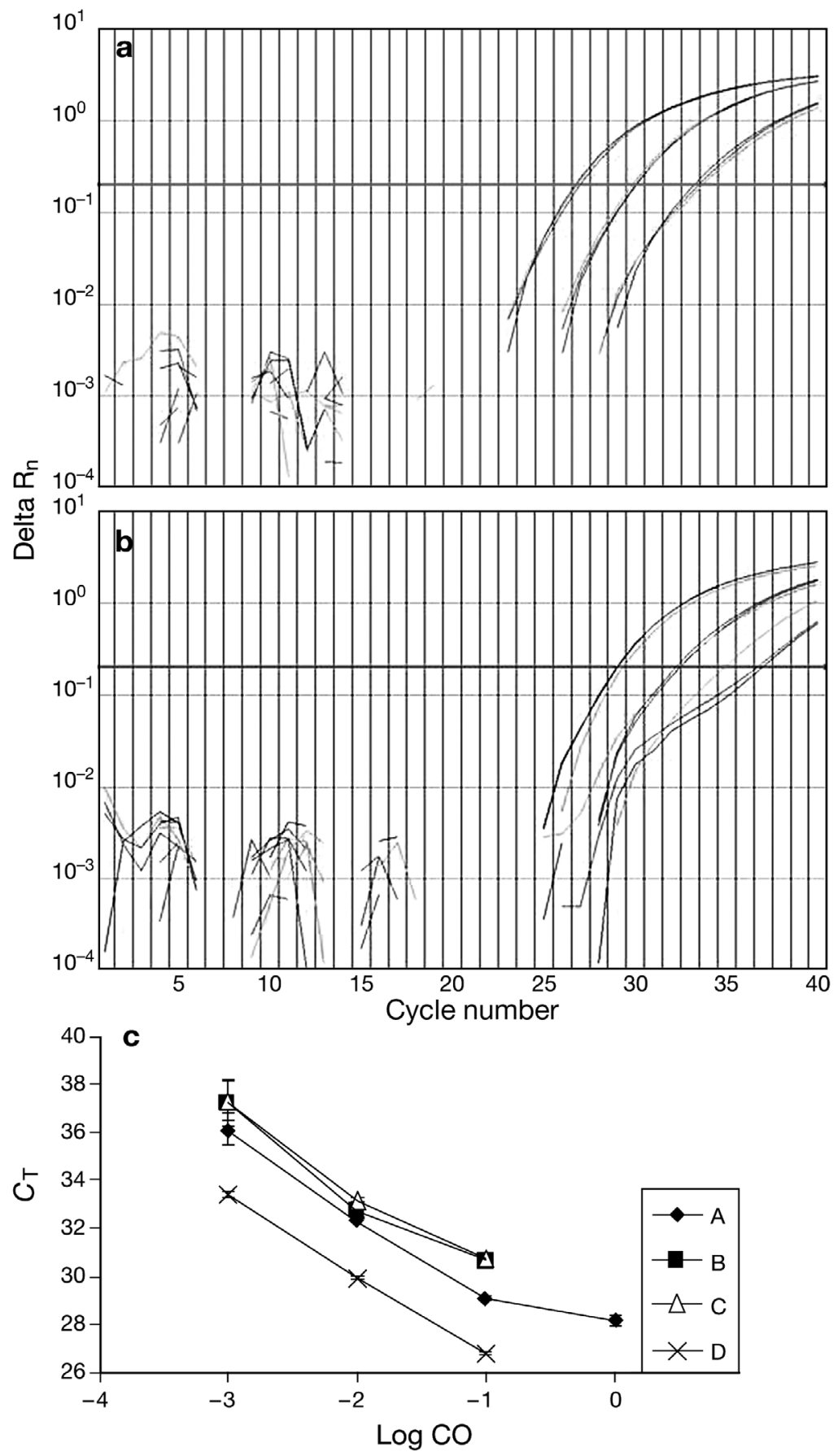

Fig. 3. Typical real-time amplification plot of replicate $(\mathrm{n}=3)$ plankton samples containing (a) 10 Lepeophtheirus salmonis copepodids or (b) $L$. salmonis copepodid. Each group of amplifications represents reactions containing $8,0.8$ or $0.08 \mathrm{ng}$ (from left to right, respectively) initial DNA template. Lack of amplification from the undiluted $80 \mathrm{ng}$ DNA reactions shows that some degree of inhibition is occurring. Delta $R_{n}$ : output fluorescence normalised against background fluorescence. Horizontal line indicates cycle threshold $\left(C_{\mathrm{T}}\right)$. (c) $C_{\mathrm{T}}$ value plotted against the logarithm of the initial DNA concentration (Log CO) of 3 plankton samples containing 1 (Samples A to C) or 10 (Sample D) copepodids (data are means $\pm \mathrm{SE}$, $\mathrm{n}=3$ ). Initial undiluted DNA concentration was $80 \mathrm{ng}$ in all samples except Sample A, which was $40 \mathrm{ng}$. No amplification was obtained from undiluted Samples B, C and D, due to PCR inhibition. Sample A has partial inhibition in its undiluted template reaction
$34.91,4.73$ cycles later than the theoretical mean control of 30.18 ; all other undiluted samples had no amplification of the IPC (Table 2). Negligible levels of inhibition were present in Samples B to D $\left(10^{-1}\right.$ diluted samples) and none was seen in the $10^{-2}$ or $10^{-3}$ dilutions.

\section{Probe application}

The triplicate DNA extractions from each plankton sample yielded similar $C_{\mathrm{T}}$ values (data not shown) and the $10^{-1}$ dilution was chosen (based on dilution vs. inhibition results) to perform a new comparable test with all samples on a single plate. These single plate molecular results are shown in Table 1 together with the microscopy results.

The Lepeophtheirus salmonis real-time PCR probe detected 20 of 22 predicted positive samples (Nos. 13 and 22 undetected) and gave a positive result in only 1 of 5 predicted negative samples (No. 17). The mean $C_{\mathrm{T}}$ values and standard deviations for samples spiked with 1, 10 and 100 L. salmonis copepodids were 37.12 $( \pm 1.53), 33.24( \pm 0.92)$ and $30.00( \pm 0.66)$. The $C_{\mathrm{T}}$ value (28.45) resulting from 1000 copepodids (No. 27) appeared higher than expected (expect approximately 3.3 cycles lower than the 100 copepodid sample) compared with the synthetic sample of 100 copepodids (28.27), suggesting a problem with this result. Ranking the L. salmonis positive samples in order of lowest $C_{\mathrm{T}}$ (first detected) to highest, showed that samples containing similar numbers of the target species could generally be grouped together over a range of $C_{\mathrm{T}}$ values (Fig. 4). The Caligus elongatus probe was positive for 3 environmental samples (Nos. 13, 14 and 17) and the 2 artificial samples (Nos. 25 and 26).

The microscopy technique failed to detect Lepeophtheirus salmonis in 3 of 22 predicted positives (Nos. 1, 6 and 10) and 1 was inconclusive as to the species of the caligid copepodid (No. 14). Of the 6 samples spiked with a single copepodid, 3 were conclusively found to contain L. salmonis. The number of $L$. salmonis copepodids recovered from the samples spiked with 10 individuals varied from 4 to 9. More than 100 caligid copepodids were found in all plankton samples spiked with 100 individuals, but only a sub-sample of 10 of these copepodids was identified to species 
Table 2. Mean $C_{\mathrm{T}}$ values $(\mathrm{n}=3)$ of internal positive controls (IPCs). Undiluted DNA was approximately $80 \mathrm{ng}$, except for Sample A, which was approximately $40 \mathrm{ng}$. All samples contained approximately $30 \mathrm{mg}$ plankton +1 (Samples A to C) or 10 (Sample D) Lepeophtheirus salmonis copepodids before DNA extraction. Controls contained $1 \mu \mathrm{l} \mathrm{dH}_{2} \mathrm{O}$ instead of DNA template. The $C_{\mathrm{T}}$ value of the control represents the theoretical value of an uninhibited reaction. A $C_{\mathrm{T}}$ value higher than this indicates later amplification and therefore inhibition. no amp.: no amplification; na: not applicable

\begin{tabular}{|lcccc|}
\hline \multirow{2}{*}{ Sample } & \multicolumn{4}{c}{ DNA } \\
\cline { 2 - 5 } & Undiluted & $10^{-1}$ & $10^{-2}$ & $10^{-3}$ \\
\hline A & 34.91 & 30.18 & 30.23 & 30.00 \\
B & no amp. & 30.77 & 29.99 & 30.01 \\
C & no amp. & 30.93 & 30.26 & 30.12 \\
D & no amp. & 31.03 & 30.12 & 30.01 \\
Control & 30.18 & na & na & na \\
\hline
\end{tabular}

level. Caligus elongatus was identified in 1 of the 2 artificial samples and was also found in 2 environmental samples (Nos. 18 and 19).

\section{DISCUSSION}

The real-time PCR probes developed in this study have been shown to be both sensitive and specific for the detection of Lepeophtheirus salmonis and Caligus elongatus. The real-time PCR assay developed for use on plankton samples was also shown to be both sensitive and specific for the detection of $L$. salmonis copepodids in environmental material.

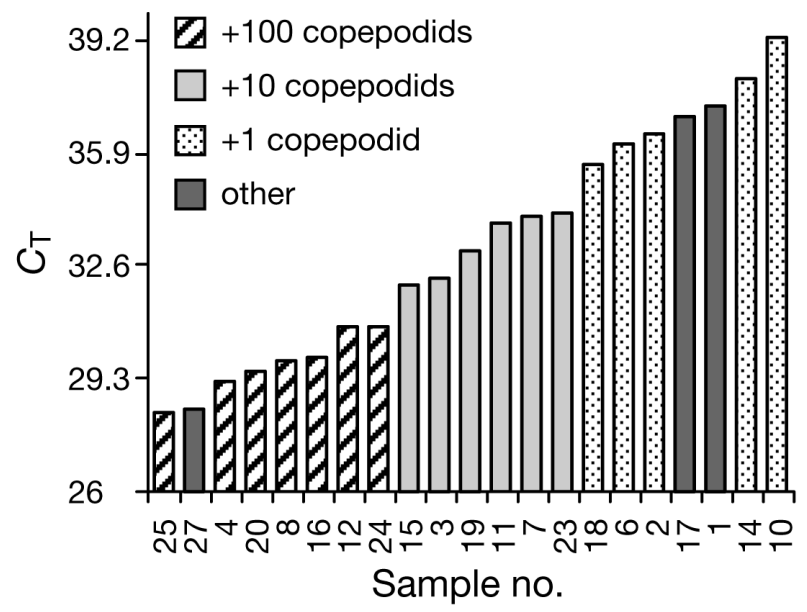

Fig. 4. Lepeophtheirus salmonis-positive samples ranked from lowest to highest $C_{\mathrm{T}}$ value. Sample Nos. 25 and 27 were artificial, containing 100 and 1000 copepodids respectively. Nos. 1 and 17 were unspiked samples, although No. 1 was considered a potentially natural positive. Sample Nos. 5, 9, 13, 21, 22, and 26 (not included in figure) were all negative for L. salmonis; Sample No. 22 was a false negative which should have been detected in the single copepodid range
Other studies incorporating genetic techniques as a means of species detection have used standard PCR followed by further steps (Medeiros-Bergen et al. 1995, Lindeque et al. 1999); however both these methodologies required the sorting of individuals first. The use of oligonucleotide probes or RFLPs requires additional post-PCR analysis in the form of lengthy incubations, followed by chemiluminescent detection or agarose gel electrophoresis, which greatly increases the analysis time. Bucklin et al. (1999) and later Hill et al. (2001) employed a form of PCR multiplexing using speciesspecific primers; this proved to be a successful method for identifying calanoid copepods, which only requires agarose gel electrophoresis following PCR, but this was also untried on unsorted plankton samples. A nested-PCR method was successfully tested on mixed plankton and water samples to detect Asterias spp. (Echinodermata: Asteroidea) larvae and was reported to have increased sensitivity over standard PCR (Deagle et al. 2003). Real-time PCR improves both the sensitivity and the specificity over standard PCR-based tests. The first level of specificity is provided by the primers, which were designed only to amplify DNA from 1 species as in regular PCR. A second level of specificity is obtained by the inclusion of the probe, which has the potential to detect even a single base difference, thus vastly reducing the likelihood of false positives. However, even with this high level of specificity, a test cannot be known to be absolutely specific without DNA sequencing of all related taxa, which is unfeasible. This applies to most if not all detection methods. The high specificity of the probe could also represent a potential disadvantage of real-time PCR. A single base change could turn a positive result into a false negative result; therefore the probes constructed for this assay were designed in conserved areas of the available COI sequence where there were no discrepancies between sequences from the same species. Taken together, these points should greatly reduce species misidentification.

The preliminary experiment demonstrated that it was possible to reproducibly detect a single copepodid in small-scale plankton samples, with $C_{\mathrm{T}}$ values comparable to the 10-fold dilution of the sample containing 10 larvae. However, significant PCR inhibition occurred in all the undiluted template reactions, as shown by very poor or complete lack of amplification of the IPCs. The inclusion of IPCs in every reaction provided a useful indicator of the level of inhibition present in each reaction. The IPCs contained in every reaction should yield a similar $C_{\mathrm{T}}$ value to those produced from the NTC reactions. A significant change in the $C_{\mathrm{T}}$ value indicates the presence of inhibitors in the template DNA. Diluting the template 10-fold appeared to be enough to remove the inhibitory effect, although 
this depends on the concentration of the starting template. Multiple factors can effect a PCR reaction such as salt and DNA concentration or exogenous factors from the extraction process (Wilson 1997, Tichopad et al. 2004). In this case, the amount of total DNA added to each reaction appeared to be an important factor; however, considering the range of materials present in a plankton sample, it is possible that some inhibitors did pass through the extraction process.

The use of the mitochondrial DNA (mtDNA) provides an advantage over the use of most nuclear genes as there are a greater number of copies of mtCOI in every cell providing a high concentration of starting template (Deagle et al. 2003), although it may not be entirely suitable for quantification purposes. The realtime PCR assay described here has a degree of quantification. Comparisons can be made between related samples analysed in the same assay run, comparing Lepeophtheirus salmonis quantities from different samples or with Caligus elongatus quantities. From Fig. 4 it can be seen that samples containing louse quantities of similar orders of magnitude can be grouped together and thus relative copepodid levels can be assessed. In theory it should be possible to differentiate at least a 10-fold difference in the initial template, which would equate to an approximate 3.33 cycle difference between 2 samples. However, application of the probes to the spiked environmental samples showed this was not the case in samples with very low target DNA concentrations. Five of the 6 samples spiked with a single copepodid were detected but the $C_{\mathrm{T}}$ values varied greatly. The variation between the 6 $C_{\mathrm{T}}$ values of the samples spiked with 10 or 100 copepodids was lower in each case, so relative quantification was more reliable in these samples. The detection of very low quantities of target DNA is often problematic and is most obvious when performing replicate 10 -fold serial dilutions of template DNA, where the highest dilutions have significant variation, suggesting the requirement for a reliable quantification 'cut-off point' for a probe. For example, using the results presented here, a $C_{\mathrm{T}}$ of higher than 35 confirms the presence of small quantities of target DNA, suggesting that the samples contain single organisms. A $C_{\mathrm{T}}<35$ confirms the presence of multiple organisms, with $<32$ suggesting that the sample contains $>10$ individuals. It is unlikely that a natural sample would contain many hundreds of larvae of a single species; however, the probes would indicate high numbers if they occurred.

Some of the environmental samples were naturally positive for Lepeophtheirus salmonis, before any spiking occurred. Two of the 6 unspiked samples were believed to be potentially positive for L. salmonis, having been collected inside cages at salmon farms, but only 1 was found to be positive by real-time PCR, and neither by microscopy. Also, 1 of the 4 believed to be potentially negative for $L$. salmonis gave a positive result with the $L$. salmonis probe. This was from the cod cage sample; however there is no record of $L$. salmonis using cod as a host. The detection of this species in a cod cage suggests either an error in sample preparation or that the louse originated from a wild source in the vicinity of the cod cage or from a near by salmon farm. L. salmonis has been recorded on other gadoid species such as saithe that are associated with fish farms in Scotland (Bruno \& Stone 1990, Lyndon \& Toovey 2001) and these may have acted as the source of the lice detected on the cod farm. Additionally it is feasible that this sample caught a naupilii or copepodid of L. salmonis transported in from elsewhere, as the planktonic stages have been recorded and mathematically modelled as travelling several kilometres from their point of origin (Krkošek et al. 2006, Murray \& Gillibrand 2006).

Each field sample collected was split into several aliquots before spiking, so if the field sample contained a small number of the target species, it is possible that one aliquot could be negative while another was positive. This was demonstrated by the detection of Caligus elongatus in only 2 of the 4 samples from the Shetland salmon cage and only 1 of the 4 cod cage samples. However, splitting of the samples was necessary to enable a comparison of the real-time method and the microscopic method using identically treated sample sets. In an applied situation the field samples would not be split unless necessary for processing, in which case the individual results would be compiled together.

In the initial stages of this study, the quantity of plankton tested in 1 reaction was limited by the DNA extraction step. The DNeasy kit manufacturer recommends $25 \mathrm{mg}$ starting tissue, which was thus the quantity selected for the first attempt. However, the method was successfully scaled up to allow 'bulk' lysis of a much larger plankton sample, mostly in the 200 to $500 \mathrm{mg}$ range, followed by DNA extraction and analysis of the lysate in triplicate. The replicate reaction results were comparable (data not shown); therefore there was little variation introduced during the DNA extraction step. It was assumed that performing the large-scale lysis produced a homogeneous lysate, containing DNA from every organism within the sample. Perhaps the addition of a specific quantity of control DNA could be introduced to demonstrate efficiency of the bulk extraction step.

The higher than expected $C_{\mathrm{T}}$ value from the artificial sample of 1000 copepodids (Sample 27) occurred due to imprecise sample preparation. The $C_{\mathrm{T}}$ value of this sample was similar to those obtained in the 6 environmental samples and 1 artificial sample containing 100 Lepeophtheirus salmonis copepodids. It was ex- 
pected that this sample would have been detected earliest, approximately 3.3 cycles before the samples containing 100 copepodids. Upon drying, Sample 27 contained a large quantity of a white precipitate, which increased the weight of the sample and, because of this, had a greater quantity of lysis buffer added to it. This sample was therefore incorrectly diluted by more than 6 -fold before the extraction step. This highlights the importance of estimating the mass of the plankton samples as accurately as possible.

The real-time PCR assay described here provides a useful alternative in the species-specific detection and identification of planktonic sea louse larvae and could be adapted for similar work across a range of target species. However, as with any method, there is potential for error and, as such, the design and application of the technique should be performed with caution. The likelihood of false positives is greatly reduced by the double level of specificity provided by the primers and, more importantly, by the Taqman ${ }^{\circledR}$ probe, but the possibility remains that an unknown similar species, with identical COI sequence in the appropriate areas could be wrongly detected. This problem also applies to traditional microscopic techniques using morphological characteristics, which are often very similar in appearance, and the use of real-time PCR lowers the potential for human error when analysing these attributes. Further application of this method is ongoing and will provide further information as to the effectiveness of this technique on field samples.

Overall, the results of the molecular and microscopic methods were comparable, demonstrating the utility of this molecular method for detecting and identifying copepodids in plankton samples. Techniques such as this could complement traditional microscopy in this area of work. Although the original aim of this study was to perform analysis on unsorted samples, a combination of the 2 methods could potentially improve sample analysis. For example, microscopy could be used to quickly sort samples and remove any caligid copepod larvae, and then the real-time PCR assay could rapidly determine the species of the larvae. This molecular method also enables identification of the species of nauplii recovered. There is difficulty in identifying nauplii, particularly nauplius I, by microscopy because the best means of determining the species at this stage utilises pigmentation characteristics; however, natural pigments are often bleached by the choice of fixative. Direct sorting of individual larvae in to 96-well plates for lysing, followed by removal of $1 \mu$ DNA-containing lysate on to the real-time reaction plate would provide an accurate and relatively fast identification method. If available, automated loading systems would increase the throughput even more, and lower the 'hands-on' time. Even without automation, over a set period, more single specimens could be analysed via this method than by microscopy and morphological means alone. The Lepeophtheirus salmonis and Caligus elongatus real-time PCR probes developed during this work provide a useful additional tool for the specific detection of the larval stages of these species in mixed plankton samples. This technique has considerable quantitative potential for use with samples collected from the environment.

Acknowledgements. The authors thank Ø. Øines and P. Heuch for supplying sequence data and also $\mathrm{S}$. Jones for supplying DNA samples. Thanks also to S. Buttle, K. Cook, S. McBeath, C. Pert, J. Raffel, B. O'Shea, D. Smallman, K. Urquhart and K. Walton for their efforts in collecting plankton samples and supplying us with copepodids.

\section{LITERATURE CITED}

Asplin L, Boxaspen K, Sandvik AD (2004) Modelled distribution of salmon lice in a Norwegian fjord. ICES CM P:11 2004/P:11

Bricknell IR, Bron JE, Bowden TJ (2006) Diseases of gadoid fish in cultivation: a review. ICES J Mar Sci 63:253-266

Brooks KM (2005) The effects of water temperature, salinity and currents on the survival and distribution of the infective copepodid stage of sea lice (Lepeophtheirus salmonis) originating on Atlantic salmon farms in the Broughton Archipelago of British Columbia, Canada. Rev Fish Sci 13:177-204

Brooks KM, Stucchi DJ (2006) The effects of water temperature, salinity and currents on the survival and distribution of the infective copepodid stage of sea lice (Lepeophtheirus salmonis) originating on Atlantic salmon farms in the Broughton Archipelago of British Columbia, Canada (Brooks, 2005) - a response to the rebuttal of Krkošek et al. (2005). Rev Fish Sci 14:13-23

Bruno DW, Stone J (1990) The role of saithe, Pollachius virens L., as a host for the sea lice Lepeophtheirus salmonis (Krøyer) and Caligus elongatus (von Nordmann). Aquaculture 89:201-208

Bucklin A, Guarnieri M, Hill RS, Bentley AM, Kaartvedt S (1999) Taxonomic and systematic assessment of planktonic copepods using mitochondrial COI sequence variation and competitive species-specific PCR. Hydrobiologia 401:239-254

Costelloe M, Costelloe J, Roche N (1996) Planktonic dispersion of larval salmon-lice Lepeophtheirus salmonis, associated with cultured salmon, Salmo salar, in Western Ireland. J Mar Biol Assoc UK 76:141-149

Costelloe M, Costelloe J, Coghlan NJ, O'Donohoe G, O'Connor B (1998a) Distribution of the larval stages of Lepeophtheirus salmonis in three bays on the west coast of Ireland. ICES J Mar Sci 55:181-187

Costelloe M, Costelloe J, O'Donohoe G, Coghlan NJ, Oonk M, Van der Heijden Y (1998b) Planktonic distribution of sea lice larvae, Lepeophtheirus salmonis, in Killary harbour, west coast of Ireland. J Mar Biol Assoc UK 78:853-874

Deagle BE, Bax N, Hewitt CL, Patil JG (2003) Development and evaluation of a PCR-based test for detection of Asterias (Echinodermata: Asteroidea) larvae in Australian plankton samples from ballast water. Mar Freshw Res 54: $709-719$ 
Folmer O, Black M, Hoeh W, Lutz R, Vrijenhoek R (1994) DNA primers for amplification of mitochondrial cytochrome c oxidase subunit I from diverse metazoan invertebrates. Mol Mar Biol Biotechnol 3:294-299

Hill RS, Allen LD, Bucklin A (2001) Multiplexed species-specific PCR protocol to discriminate four N. Atlantic Calanus species, with an mtCOI gene tree for ten Calanus species. Mar Biol 139:279-287

Jackson D, Michin D, Duggan C, Hassett D, Leahy Y, Whitaker A (1994) Observation of the larval stages of the salmon louse, Lepophtheirus salmonis. ICES CM F:15

Johnson SC, Albright LJ (1991a) The developmental stages of Lepeophtheirus salmonis (Krøyer, 1837) (Copepoda, Caligidae). Can J Zool 69:929-250

Johnson SC, Albright LJ (1991b) Development, growth and survival of Lepeophtheirus salmonis (Copepoda: Caligidae) under laboratory conditions. J Mar Biol Assoc UK 71:425-436

Johnson SC, Treasurer JW, Bravo S, Nagasawa K, Kabata Z (2004) A review of the impact of parasitic copepods on marine aquaculture. Zool Stud 43:229-243

Krkošek M, Lewis MA, Volpe JP (2005) Transmission dynamics of parasitic sea lice from farm to wild salmon. Proc $\mathrm{R}$ Soc Lond Ser B 272:689-696

Krkošek M, Lewis MA, Volpe JP (2006) Fish farms and sea lice infestations of wild juvenile salmon in the Broughton Archipelago-a rebuttal to Brooks (2005). Rev Fish Sci 14:1-11

Lindeque PK, Harris RP, Jones MB, Smerdon GR (1999) Simple molecular method to distinguish the identity of Calanus species (Copepoda: Calanoida) at any developmental stage. Mar Biol 133:91-96

Lindeque PK, Harris RP, Jones MB, Smerdon GR (2004) Distribution of Calanus spp. as determined using a genetic identification system. Sci Mar 68(Suppl 1):121-128

Lyndon AR, Toovey JPG (2001) Occurrence of gravid salmon lice (Lepeophtheirus salmonis (Krøyer)) on saithe (Pollachius virens) from salmon farm cages. Bull Eur Assoc Fish Pathol 21:84-85

McKibben MA, Hay DW (2004) Distributions of planktonic sea lice larvae Lepeophtheirus salmonis in the intertidal zone in Loch Torridon, Western Scotland in relation to salmon farm production cycles. Aquac Res 35:742-750

Medeiros-Bergen DE, Olson RR, Conroy JA, Kocher TA (1995) Distribution of holothurian larvae determined

Editorial responsibility: Robin Overstreet, Ocean Springs, Mississippi, USA with species-specific genetic probes. Limnol Oceanogr 40: 1225-1235

Murray AG, Gillibrand PA (2006) Modelling salmon lice dispersal in Loch Torridon, Scotland. Mar Pollut Bull 53: 128-135

Øines Ø, Heuch PA (2005) Identification of sea louse species of the genus Caligus using mtDNA. J Mar Biol Assoc UK 85:73-79

Øines Ø, Simonsen JH, Knutsen JA, Heuch PA (2006) Host preference of adult Caligus elongatus Nordmann in the laboratory and its implications for Atlantic cod aquaculture. J Fish Dis 29:167-174

Penston MJ, McKibben MA, Hay DW, Gillibrand PA (2004) Observations on open-water densities of sea lice larvae in Loch Shieldaig, Western Scotland. Aquaculture Res 35: 793-805

Piasecki W (1996) The developmental stages of Caligus elongatus von Nordmann, 1832 (Copepoda: Caligidae). Can J Zool 74:1459-1478

Pike AW, Wadsworth SL (1999) Sea lice on salmonids: their biology and control. Adv Parasitol 44:233-337

Rae GH (2002) Sea louse control in Scotland, past and present. Pest Manag Sci 58:515-520

Revie CW, Gettinby G, Treasurer JW, Rae GH, Clark N (2002) Temporal, environmental and management factors influencing the epidemiological patterns of sea lice (Lepeophtheirus salmonis) infestations on farmed Atlantic salmon (Salmo salar) in Scotland. Pest Manag Sci 58:576-584

Schram TA (1993) Supplementary descriptions of the developmental stages of Lepeophtheirus salmonis (Krøyer, 1837) (Copepoda: Caligidae). In: Defaye D (ed) Sea lice; pathogens of wild and farmed fish. Ellis Horwood, Chichester, p 30-47

Schram TA (2004) Practical identification of pelagic sea lice larvae. J Mar Biol Assoc UK 84:103-110

Tichopad A, Didier A, Pfaffl MW (2004) Inhibition of real-time RT-PCR quantification due to tissue-specific contaminants. Mol Cell Probes 18:45-50

Wilson IG (1997) Inhibition and facilitation of nucleic acid amplification. Appl Environ Microbiol 63:3741-3751

Wootten R, Smith JW (1982) Aspects of the biology of the parasitic copepods Lepeophtheirus salmonis and Caligus elongatus on farmed salmonids, and their treatment. Proc R Soc Edinb Sect B 81:185-197

Submitted: June 8, 2006; Accepted: September 12, 2006 Proofs received from author(s): December 6, 2006 